\title{
Evaluation of a nutrition supplementation programme in the Northern Cape Province of South Africa
}

\author{
MK Hendricks ${ }^{1, *}$, M le Roux ${ }^{2}, M$ Fernandes ${ }^{2}$ and J Irlam ${ }^{1}$ \\ ${ }^{1}$ Child Health Unit, School of Child and Adolescent Health, University of Cape Town, 46 Sawkins Road, \\ Rondebosch 7700, Cape Town, South Africa: ${ }^{2}$ Nutrition Sub-directorate, Department of Health, Northern Cape, \\ South Africa
}

Submitted 16 September 2002: Accepted 8 January 2003

\begin{abstract}
Aim: This study aimed at assessing the effectiveness regarding implementation and impact of a take-home nutrition supplementation programme, the Protein Energy Malnutrition (PEM) Scheme, that targets malnourished pre-school children and pregnant and lactating women in the Northern Cape Province of South Africa.

Methodology: In assessing implementation of the PEM Scheme, a cross-sectional descriptive study was undertaken over a 6-month period in the six regions of the Northern Cape Province. Interviews were conducted with programme managers and health personnel at clinics who were responsible for implementing the PEM Scheme. In assessing the impact of the PEM Scheme on growth, a retrospective review was done of the clinic records (including anthropometric data) of children enrolled in the PEM Scheme over a 1-year period.

Results: About $76 \%$ of the budget allocated to the PEM Scheme had been utilised over the 1-year period. The budget for the following financial year was based solely on food supplements purchased in the previous year. Coverage of malnourished preschool children and eligible pregnant and lactating women for enrolment was estimated to be $50 \%$ and $60 \%$, respectively. Eighty-five per cent of health facilities in the province participated in the PEM Scheme. Some of the main problems identified included: lack of training, inappropriate targeting of certain groups, incorrect application especially of discharge criteria for pregnant and lactating women, inadequate assessment for nutrition-related disease, inadequate nutrition counselling and no standardised monitoring. Of the 319 children enrolled over a year, the mean age was 16.2 (standard deviation 16.2) months, $41 \%$ had been low-birth-weight and $18 \%$ had been diagnosed with tuberculosis. Ten per cent of the children with a weight-for-age $Z$-score of $<-2$ moved into the normal $Z$-score range after being on the PEM Scheme for a mean duration of 8 months. There was an overall improvement in the weight-for-age $Z$-scores of $25 \%$ of the sample, with a significant difference between the mean weight-for-age $Z$-scores at enrolment and follow-up $(t=4.8$, $P<0.001)$. This was mainly related to significant improvement in the mean weightfor-age $Z$-scores of children $<2$ years.

Conclusions: Numerous problems with the PEM Scheme have been identified which could have limited its impact. Recommendations are proposed for improving the effectiveness and impact of the PEM Scheme in the province.
\end{abstract}

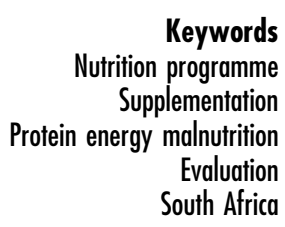

Although the Northern Cape Province occupies 30\% of the surface area of South Africa (Fig. 1), its total population size is only 763806 , resulting in the lowest population density nationally ${ }^{1}$. About $34 \%$ of the population are less than 15 years of age ${ }^{1}$. The National Food Consumption Survey (1999) of children 1-9 years of age showed that $23.7 \%$ (confidence interval (CI) 16.4-31) had a weight-forage $Z$-score less than minus two standard deviations $(<-2 \mathrm{SD}), 29.6 \%$ (CI 21.8-37.4) had a height-for-age $Z$-score of $<-2$ SD and 9.6\% (CI 4.6-14.7) had a weightfor-height $Z$-score of $<-2$ SD from the mean of reference values of the National Center for Health Statistics (NCHS) ${ }^{2}$. These rates are higher than the national average for stunting (21.6\%), underweight (10.3\%) and wasting $(3.7 \%)^{2}$. Marginal vitamin A deficiency and iron-deficiency anaemia were previously found to be prevalent among $18.5 \%$ and $10.9 \%$ of children aged $6-71$ months of age, respectively ${ }^{3}$.

One of the main ways of addressing malnutrition in the Northern Cape and other provinces has been through a state-subsidised nutrition intervention programme, the Protein Energy Malnutrition (PEM) Scheme, which has 


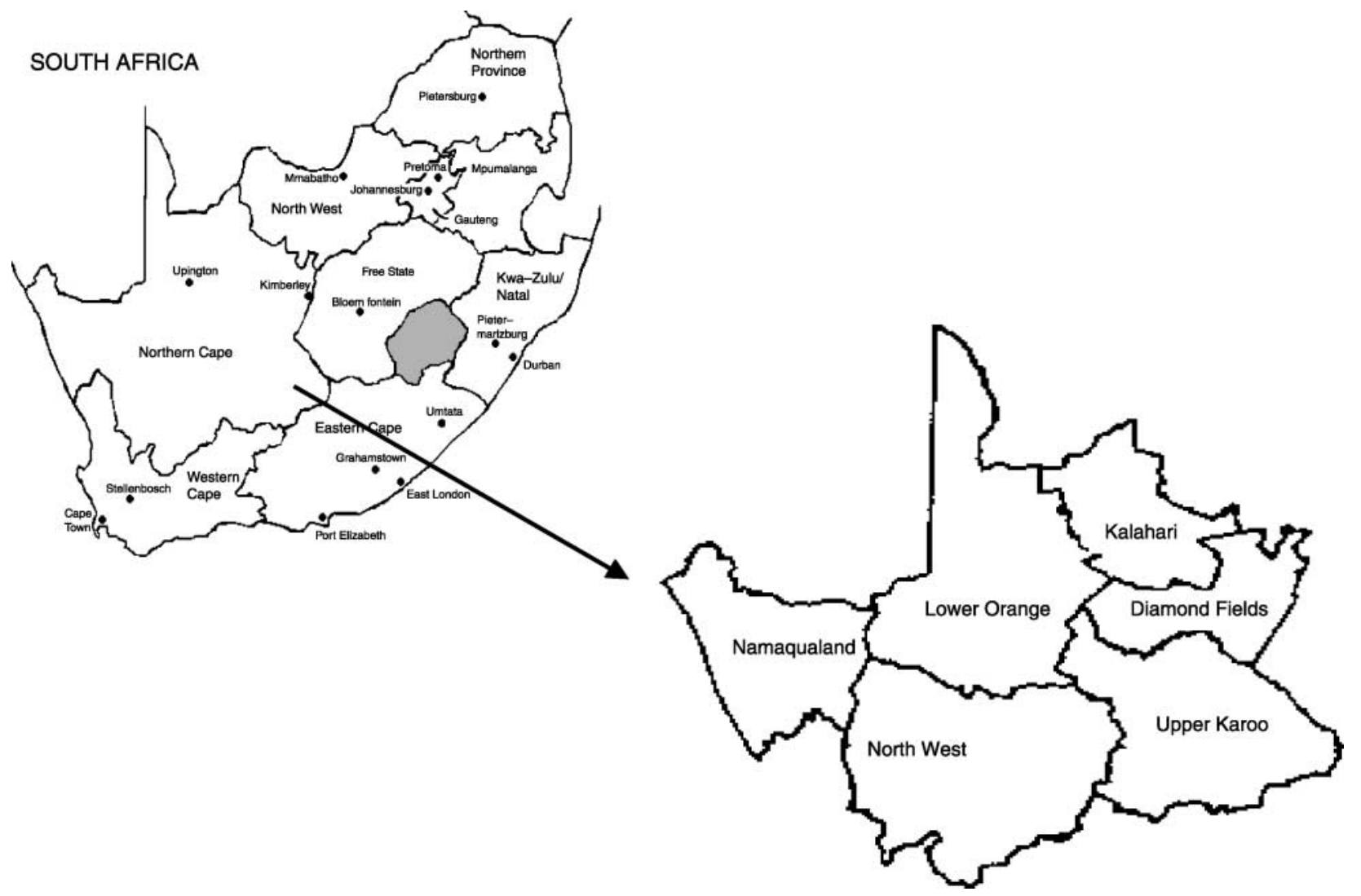

Fig. 1 Geographical location and regions of the Northern Cape Province of South Africa

been in existence since $1960^{4}$. The PEM Scheme was aimed at children from 6 months to 6 years old who visited local authority clinics and who, according to growth charts, were suffering from or at risk of malnutrition. In 1991 the PEM Scheme was extended to other vulnerable groups such as pregnant and lactating women, the aged and those chronically ill. In 1994, following the development of the Integrated Nutrition Programme, it was recommended that the PEM Scheme be integrated into the broader health facility-based (clinic or community health centre) programme together with other primary healthcare nutrition-related interventions such as growth monitoring, case management of nutrition-related disease, counselling and micronutrient supplementation ${ }^{4}$.

Currently, the PEM Scheme provides food supplements to children $<6$ years, pregnant and lactating women and those with chronic illness. Specific criteria need to be met for entry to the PEM Scheme by these target groups. These include underweight or growth faltering for at least two consecutive months for children $<6$ years old; body mass index (BMI) of $<18.5 \mathrm{~kg} \mathrm{~m}^{-2}$ or poor weight gain for pregnant women; growth faltering in the infant or maternal BMI $<18.5 \mathrm{~kg} \mathrm{~m}^{-2}$ for lactating women; and underweight or poor weight gain for the chronically ill. Criteria for discharge from the PEM Scheme include adequate weight gain for three consecutive months for children $<6$ years; following delivery in pregnant women; following discontinuation of breast-feeding in lactating women; and adequate weight gain in the chronically ill 5 .

Supplements provided at monthly clinic visits include $2 \mathrm{~kg}$ of full-cream milk powder to infants $0-71$ months of age and $4 \mathrm{~kg}$ of a protein, vitamin and mineral (PVM) mixture to infants and children 6-71 months. Pregnant and lactating women are provided at monthly clinic visits with $1 \mathrm{~kg}$ of full-cream milk powder and $4 \mathrm{~kg}$ of PVM mixture. The PVM mixture is a fortified maize and milk mixture and each $100 \mathrm{~g}$ provides $450 \mathrm{kcal}$ of energy, $12.5 \mathrm{~g}$ of protein, $60 \mathrm{~g}$ of carbohydrate and $17 \mathrm{~g}$ of fat. It is also enriched (per $100 \mathrm{~g})$ with vitamin A $(400 \mu \mathrm{g}$ retinol equivalents), thiamin $(0.7 \mathrm{mg})$, riboflavin $(0.8 \mathrm{mg})$, niacin (8.9 mg), vitamin $B_{6}(0.9 \mathrm{mg})$, vitamin $\mathrm{B}_{12}(0.66 \mu \mathrm{g})$, vitamin C ( $44.5 \mathrm{mg})$, vitamin D (10 $\mu \mathrm{g})$, vitamin E $(5 \mathrm{mg})$, biotin $(13.2 \mu \mathrm{g})$, folic acid $(49.5 \mu \mathrm{g})$, pantothenic acid (1.98 mg), calcium (528 mg), phosphorus (528 mg), potassium ( $400 \mathrm{mg}$ ), iron (10 mg), magnesium (66 mg), zinc $(6.6 \mathrm{mg})$, iodine $(46 \mu \mathrm{g})$, sodium $(198 \mathrm{mg})$ and selenium $(13.2 \mu \mathrm{g})$ (L Steenkamp, DIVA, personal communication, 2002).

There have been no provincial or national evaluations of the PEM Scheme since its inception. The current study arose following a request by the Nutrition Sub-directorate for an evaluation of how effectively the PEM Scheme has been implemented and what its impact has been on the growth of children in the Northern Cape Province of South Africa. 
Methodology

\section{Study area}

The Northern Cape Province is divided into six regions (Fig. 1) which, because of the low population numbers and density, also function as health districts. These regions are Lower Orange, North West, Upper Karoo, Diamond Fields, Namaqualand and Kalahari. Diamond Fields has the largest population (309668) followed by Lower Orange (137 182), Upper Karoo (124571), Kalahari (84864), Namaqualand (65904) and North West (42 287). About $27 \%$ of the population are rural, living mainly in the Lower Orange (42\%) and North West (37\%) regions ${ }^{1}$.

This was a cross-sectional descriptive study and data for the entire study were collected over a 6-month period; this included the evaluation of the implementation of the PEM Scheme as well as its impact on the growth of participating children in the Northern Cape.

\section{Implementation of the PEM Scheme}

Nutrition programme managers were interviewed to assess policy implementation, budgetary allocations, target groups, distribution of supplements, training and monitoring.

Provincial data relating to the Scheme were reviewed to obtain information on the number of children $<6$ years and pregnant and lactating women enrolled, budgets allocated to and clinics participating in the Scheme.

We aimed to cover all clinics in the province that participated in the PEM Scheme. Structured interviews were conducted with the professional nurse (respondent) from each of the selected clinics. The interviews were aimed at assessing availability and knowledge of the PEM policy document, groups targeted, criteria for enrolment and discharge, nutrition counselling, clinical assessment for disease, referrals to community-based projects, the identification of problems with the Scheme and suggestions for improving implementation of the PEM Scheme.

A dietitian/nutritionist who was supervised by a provincial dietitian/nutritionist in the Nutrition Subdirectorate conducted all the interviews with the clinic respondents. All interviews were conducted in the respondents' home language at the clinics where they worked by the same dietitian/nutritionist to avoid interobserver bias. All of the questionnaires were piloted and mistakes or ambiguities were corrected prior to the survey.

\section{Impact of the PEM Scheme}

To assess the impact of the PEM Scheme on the growth status of the children enrolled, a retrospective review was undertaken of clinic records of participating children over a 1-year period. The data were transposed from the clinic records on to a standardised form, which had previously been tested in a pilot survey. The same dietitian/nutritionist who conducted the interviews undertook the retrospective data collection.
An assessment was made of the number of clinics, which kept records, percentage of children who were lowbirth-weight, weight-for-age of the children at enrolment and discharge, the presence of underlying diseases such as tuberculosis and HIV/AIDS and the number of children who defaulted.

The data relating to both objectives were analysed using Epi-Info 6 and Anthro software. Summary statistics (percentages, means and SDs) were determined for the descriptive variables. In terms of anthropometry, underweight was expressed as the proportion of individuals with $Z$-scores $<-2 \mathrm{SD}$ from the mean of reference values of the NCHS.

In order to assess the impact of the Scheme on the anthropometric status of children according to gender and age (above and below 2 years), the mean weight-for-age $Z$-scores of the children were compared at the first visit (i.e. at entry) and at the last visit (i.e. at exit). If nutrition supplementation had an effect on the weight gain, one would have expected a significant increase in the weightfor-age $Z$-scores at the last visit. To test this hypothesis, the paired $t$-test was used to compare the weight-for-age $Z$-scores at the first and last visits.

\section{Results}

\section{Implementation of the PEM Scheme}

A total of R690 695 out of R904750 (i.e. 76\%) allocated to the PEM Scheme in the province was spent over the 1-year period (1996-97). This was mainly used for the purchase of food supplements, with the amount spent being used to calculate the budget for the purchase of supplements for the following financial year (1997-98). During 1996, 10000 children <6 years old and 1698 pregnant and lactating women were enrolled in the PEM Scheme. Based on an estimate of $16.5 \%$ of children $<6$ years and using a $15.6 \%$ prevalence of underweight, there were about 19000 underweight children ( $<6$ years) in the province over this period $^{3}$. The PEM Scheme therefore covered about $50 \%$ of malnourished children provincially during 1996. Using 15645 live births (1996) and a low-birth-weight rate previously found to be $18 \%, 2800$ pregnant women would have been eligible for enrolment into the PEM Scheme ${ }^{6}$. Coverage of pregnant and lactating women, based on these estimates, was 60\% for 1996.

Three nutritionists were responsible for overseeing the implementation of the PEM Scheme in the six regions of the province. Fifteen nutrition advisors rotated through the various clinics in the regions where they were based and assisted with weighing the children and nutrition education. Of the nutrition advisors, three were in Diamond Fields, five in Lower Orange, one in Kalahari and six in Namaqualand. Clinic staff received no formal training in implementing the PEM Scheme. Monitoring of the PEM Scheme provincially included record keeping of the target groups and supplements distributed, regionally. 
This was based on the claim forms submitted every three months by the health facilities in the various regions. Record keeping of children on the Scheme was done at the discretion of the health facilities and was not standardised.

Ninety-three out of 110 clinics (85\%) participated in the PEM Scheme. The proportion of health facilities participating in each of the regions is outlined in Table 1 , and ranged from $63 \%$ in Namaqualand to $94 \%$ in Diamond Fields. We were able to assess the implementation of the PEM Scheme at 78 (84\%) of the clinics, which included 23 (30\%) from Diamond Fields, 18 (23\%) from Lower Orange, 17 (22\%) from Upper Karoo, eight (10\%) from Namaqualand, seven (9\%) from Kalahari and five (6\%) from the North West region. Fifteen of the participating clinics could not be reached because they were too remote or were operating as mobile clinics.

Seventy respondents (90\%) said that their clinics were in possession of the PEM Scheme policy document (Table 2). Respondents said that they mainly targeted infants $<6$ months (83\%), children 6-71 months (91\%), pregnant women (64\%) and lactating women (67\%). Groups not in the policy document but also targeted included children $>71$ months (36\%), siblings of children on the PEM Scheme (27\%) and unemployed individuals (9\%).

Of the respondents, correct criteria for enrolment into the Scheme were applied by $71 \%$ for children aged 0-6 months, 97\% for children aged 6-71 months, 69\% for pregnant mothers and $71 \%$ for lactating mothers. Correct discharge criteria were applied by $94 \%$ for children aged 6-71 months, 58\% for pregnant mothers and 58\% for lactating mothers. Children enrolled were assessed for underlying disease by $92 \%$. The main conditions assessed for included tuberculosis (57\%), severe malnutrition (17\%), diarrhoea (13\%), parasites (7\%) and HIV (6\%).

Nutrition counselling was provided at each visit by $67 \%$. Respondents counselled mothers/caregivers about preparation of the supplements (40\%), balanced diets and regular meals (33\%), breast-feeding (17\%), hygiene (8\%) and family planning $(2 \%)$.

Forty-three (55\%) identified problems with the Scheme. Problems cited included supplements not reaching the

Table 1 Selection of clinics participating in the PEM Scheme

\begin{tabular}{lccrr}
\hline Region & $\begin{array}{c}\text { Number } \\
\text { of clinics }\end{array}$ & $\begin{array}{c}\text { Number } \\
\text { participating } \\
(\%)\end{array}$ & $\begin{array}{c}\text { Number } \\
\text { selected } \\
(\%)\end{array}$ & $\begin{array}{c}\text { \% of total } \\
\text { selected }\end{array}$ \\
\hline Diamond Fields & 32 & $30(94)$ & $23(77)$ & 30 \\
Lower Orange & 24 & $22(92)$ & $18(82)$ & 23 \\
Upper Karoo & 18 & $16(89)$ & $17(85)$ & 22 \\
Kalahari & 10 & $8(80)$ & $7(88)$ & 9 \\
Namaqualand & 16 & $10(63)$ & $8(80)$ & 10 \\
North West & 10 & $7(70)$ & $5(71)$ & 6 \\
Total & 110 & $93(85)$ & $78(84)$ & 100 \\
\hline
\end{tabular}

PEM Scheme - Protein Energy Malnutrition Scheme, targeting malnourished pre-school children and pregnant and lactating women in the Northern Cape Province of South Africa.
Table 2 Implementation of the activities of the PEM Scheme by clinics ( $n=78$ respondents)

\begin{tabular}{lc}
\hline Activity & $\begin{array}{c}\text { Number } \\
\text { implementing } \\
\text { activity (\%) }\end{array}$ \\
\hline Clinic in possession of policy & $70(90)$ \\
Groups targeted & $65(83)$ \\
Infants 0-6 months & $71(91)$ \\
Children 6-71 months & $50(64)$ \\
Pregnant women & $52(67)$ \\
Lactating women & \\
Correct enrolment criteria applied & $55(71)$ \\
Infants 0-6 months & $74(97)$ \\
Children 6-71 months & $54(69)$ \\
Pregnant women & $55(71)$ \\
Lactating women & \\
Children 6-71 months & $73(94)$ \\
Pregnant women & $45(58)$ \\
Lactating women & $45(58)$ \\
Assessment for disease & $72(92)$ \\
Nutrition counselling at each visit & $52(67)$ \\
\hline
\end{tabular}

PEM Scheme - Protein Energy Malnutrition Scheme, targeting malnourished pre-school children and pregnant and lactating women in the Northern Cape Province of South Africa.

intended groups (23\%), dependency on the supplements (21\%), irregular clinic attendance (21\%), irregular supplement supplies (19\%), poor control over supplement usage (5\%), unacceptability of supplements (5\%), withdrawal of certain supplements (2\%), no supplements for children with allergies (2\%) and inappropriate targeting of certain groups (2\%).

Thirty-four (44\%) made suggestions for improving the Scheme. These included making more supplies and resources available (32\%), supervised feeding (24\%), regular supplies (12\%), more personnel to run the Scheme (12\%), selling products for a small fee (6\%), modification of entry and exit criteria (6\%), developing communitybased projects for managing malnourished children (6\%) and restriction of the PEM Scheme to rural areas (2\%).

\section{Impact of the PEM Scheme}

Of the 78 clinics assessed, 34 (44\%) had records of children on the PEM Scheme. Of the records reviewed, 319 out of $386(83 \%)$ were complete and suitable for analysis. There were 184 girls (58\%) and 135 boys (42\%). The mean age of the children enrolled was 16.2 (SD 16.2) months. Birth weight records could be obtained for only 222 of the children. Of these, 92 children (41\%) were low-birthweight (birth weight $<2.5 \mathrm{~kg}$ ). Of the entire sample, 58 (18\%) had tuberculosis and one had HIV. Twenty of the children (6.5\%) had defaulted from the Scheme.

The weight-for-age $Z$-scores of the sample at the first visit and at a mean duration on the scheme of 8 months later are shown in Tables 3 and 4 . At the first visit, 65\% had a weight-for-age $Z$-score of $<-2$, with a mean score of -2.5 (S.D 1.4). At follow-up, 8 months later, 55\% had a weight-for-age $Z$-score of $<-2$, with a mean score of -2.1 (SD 1.2). Although only $10 \%$ of the children who had 
Table 3 Weight-for-age Z-scores at baseline for children enrolled in the PEM Scheme (values given as $n(\%)$ )

\begin{tabular}{|c|c|c|c|c|c|c|c|c|}
\hline \multirow[b]{2}{*}{ Age } & \multirow[b]{2}{*}{ Gender } & \multirow[b]{2}{*}{$n$} & \multicolumn{6}{|c|}{ Z-score* } \\
\hline & & & $<-2$ & -2 to -1 & -1 to 0 & 0 to 1 & 1 to 2 & $>2$ \\
\hline \multirow[t]{2}{*}{$0-24$ months } & Boys & 110 & $75(68)$ & $23(21)$ & $7(6)$ & $3(3)$ & $2(2)$ & $0(0)$ \\
\hline & Girls & 144 & $88(61)$ & 37 (26) & $12(8)$ & $5(4)$ & $2(1)$ & $0(0)$ \\
\hline \multirow{2}{*}{ 24-72 months } & Boys & 25 & $18(72)$ & $6(24)$ & $1(4)$ & $0(0)$ & $0(0)$ & $0(0)$ \\
\hline & Girls & 40 & $25(63)$ & $12(30)$ & $2(5)$ & $1(2)$ & $0(0)$ & $0(0)$ \\
\hline $0-72$ months & Boys and girls & 319 & $206(65)$ & $79(24)$ & $22(7)$ & $9(3)$ & $4(1)$ & $0(0)$ \\
\hline
\end{tabular}

PEM Scheme - Protein Energy Malnutrition Scheme, targeting malnourished pre-school children and pregnant and lactating women in the Northern Cape Province of South Africa.

* Standard deviations from the mean of reference values of the National Center for Health Statistics.

$Z$-scores of $<-2$ moved into the acceptable $Z$-score range, there was an overall improvement in the $Z$-scores in $25 \%$ of the sample. There was a significant difference for the whole sample between the mean weight-for-age $Z$-scores at enrolment and at the 8-month follow-up visit $(t=4.8, P<0.001)$.

For children aged $<24$ months there was a significant difference in the mean weight-for-age $Z$-scores between the first visit (mean $-2.38, \mathrm{SD} 1.27$ ) and the last visit (mean -1.93 , SD 1.28) $(t=13.8, P<0.001)$. For children aged $>24$ months no significant difference was found in the mean weight-for-age $Z$-scores between the first visit (mean -2.55 , SD 1.27) and the last visit (mean -2.42 , SD 0.97) $(t=0.59, P=0.4)$.

No significant differences were found in the weight-forage $Z$-score difference between the first and last visits (mean, SD) of children attending clinics where nutrition advisors were based and where they were not based: Diamond Fields $(0.4,1.3)$, Kalahari $(0.4,1.1)$, Lower Orange $(0.4,1.1)$, Namaqualand $(-0.4,1.1)$, North West $(0.3,0.5)$ and Upper Karoo $(0.4,1.6)$.

\section{Discussion}

\section{Implementation of the PEM Scheme}

The PEM Scheme in the Northern Cape operated essentially as a food-based programme, with budgets based on food supplements purchased during the previous financial year and without taking into account the cost of nutrition-related interventions such as growth monitoring, standardised case management, nutrition promotion, training, monitoring and evaluation. This probably limited staff in comprehensively managing malnourished children and pregnant and lactating mothers. Also notable was the absence of linkages of the Scheme to sustainable initiatives such as communitybased income generation projects, which were not in place.

The coverage rate of malnourished children was low compared with that in successful programmes like the Joint World Health Organization/United Nations Childrens Fund Nutrition Support Programme in Tanzania and the Tamil Nadu Integrated Nutrition Project in India, where programme coverage was estimated to be 70 and $95 \%$, respectively ${ }^{7}$. Coverage of $50 \%$ of malnourished children in the province is probably an overestimate of the true coverage rate as it excluded children with growth faltering who would have been eligible for inclusion. Coverage of pregnant and lactating women was also low compared with similar nutrition programmes involving pregnant women ${ }^{7}$.

Lack of awareness concerning the inclusion of high-risk pregnant and lactating women in the PEM Scheme by about a third of the clinic staff probably contributed to the low coverage of this group. Children $>6$ years old, siblings of children on the PEM Scheme and the unemployed were inappropriately targeted. The high number of infants $<6$ months that were targeted is in conflict with the National Breast-feeding Policy 5 . The reason for this may be due to the high number of lowbirth-weight babies enrolled, many of whom were probably not breast-fed.

Table 4 Weight-for-age Z-scores at last visit for children enrolled in the PEM Scheme (values given as $n(\%)$ )

\begin{tabular}{|c|c|c|c|c|c|c|c|c|}
\hline \multirow[b]{2}{*}{ Age } & \multirow[b]{2}{*}{ Gender } & \multirow[b]{2}{*}{$n$} & \multicolumn{6}{|c|}{$Z$-score* } \\
\hline & & & $<-2$ & -2 to -1 & -1 to 0 & 0 to 1 & 1 to 2 & $>2$ \\
\hline \multirow[t]{2}{*}{$0-24$ months } & Boys & 81 & $43(53)$ & $20(24)$ & $7(9)$ & $7(9)$ & $2(2.5)$ & $2(2.5)$ \\
\hline & Girls & 115 & $55(48)$ & 42 (37) & $13(11)$ & $3(2)$ & $1(1)$ & 1 (1) \\
\hline \multirow[t]{2}{*}{ 24-72 months } & Boys & 53 & $39(74)$ & $12(22)$ & $2(4)$ & $0(0)$ & $0(0)$ & $0(0)$ \\
\hline & Girls & 70 & $39(56)$ & $23(33)$ & $6(8)$ & $2(3)$ & $0(0)$ & $0(0)$ \\
\hline $0-72$ months & Boys and girls & 319 & $176(55)$ & $97(30)$ & $28(9)$ & $12(4)$ & $3(1)$ & $3(1)$ \\
\hline
\end{tabular}

PEM Scheme - Protein Energy Malnutrition Scheme, targeting malnourished pre-school children and pregnant and lactating women in the Northern Cape Province of South Africa.

* Standard deviations from the mean of reference values of the National Center for Health Statistics. 
There were fundamental aspects relating to implementation of the PEM Scheme where the respondents lacked knowledge. These included application of the appropriate enrolment and discharge criteria for pregnant and lactating mothers; and assessment for illness, especially HIV (which is on the increase and requires more vigilance), anaemia and foetal alcohol syndrome. None of the respondents counselled mothers on issues such as proper dietary practices during pregnancy and lactation, complementary feeding, feeding during illness, food purchasing and diets to avoid diseases of lifestyle. Improved knowledge of these aspects through training could result in a greater impact of the PEM Scheme on the nutritional status of mothers and children.

One of the problems that respondents identified included supplements not reaching the right target groups. This may have been related to concerns about dilution of supplements within the household, which is a common phenomenon in many supplementary feeding programmes. In take-home distribution programmes only $40-60 \%$ of the food was found to be consumed by the target child, even when supplements were given to other household members ${ }^{8,9}$. There also appeared to be no difference in weight gain of children on a take-home programme compared with those on a supervised one ${ }^{10}$. Concerns about irregular supplies and clinic attendance could certainly have reduced the nutritional impact of the PEM Scheme, and these need to be addressed through appropriate action.

\section{Impact of the PEM Scheme}

Only $10 \%$ of underweight children moved back into the normal percentile range, which is in keeping with the results of other studies but where no significant change could be detected in the growth of the children because of constraints in sample size $\mathrm{e}^{11,12}$. These results contrast with those for moderately wasted 6-24-month-old Guatemalan children given moderate (Atole) and low (Fresco) energy supplements. The 3-month recovery rates of the children ranged from 29 to $52 \%$, and children in the Atole group consumed $>10 \%$ of their recommended dietary intake from the supplement. Based on their findings, the authors of this study concluded that food supplementation could have strong beneficial effects on the rehabilitation of malnourished children ${ }^{13}$.

A limitation of our study was the lack of data on the heights of children admitted to the PEM Scheme, as stunting may have contributed to poor catch-up growth of some of the children. However, food supplementation can result in a reversal in the process of stunting provided nutrition intervention takes place before 36 months of age $^{14}$. This supports supplementary feeding of children $<3$ years of age, where the process of stunting could be reversed. Supplementation of older children who have become stunted is likely to lead to obesity, as has been found in the Chilean Supplementary Feeding Programme.
Based on this, the criteria for supplementary feeding of children $>2$ years in Chile are now being based on a weight-for-height rather than a weight-for-age $Z$-score of $<-2 \mathrm{SD}^{15}$. The results of our study also indicate that the growth of children $<2$ years old improved significantly compared with children $>2$ years old, where little change was noted, thereby further supporting dietary supplementation of younger children.

Numerous other factors may have limited the Scheme's impact on the growth of children and in effecting a positive outcome in pregnant and lactating mothers. The high low-birth-weight rate among children on the PEM Scheme in this study is in keeping with other studies and probably is a major contributor to the high prevalence of malnutrition among children in the province. Low birth weight has been noted to be a determinant in $20-40 \%$ of children with chronic malnutrition in the first two years of life ${ }^{16}$. Studies show that supplementation of pregnant women can decrease perinatal mortality and the incidence of low birth weight, particularly when the mother has low weight-for-height, low prenatal weight and low calorie intake ${ }^{8,17}$. Supplementation can also influence the growth of offspring beyond the intrauterine period, as was shown in a comparative study in East Java using a high-energy and a low-energy supplement in two groups of pregnant women. Compared with the low-energy supplement group, children in the high-energy supplement group were heavier at 2 years and taller at 5 years of age ${ }^{18}$. There also is evidence that supplementation of lactating mothers increases milk yield and therefore could positively influence the duration of exclusive breast-feeding ${ }^{19}$.

Food supplementation of malnourished mothers and children is probably necessary in the light of the recent findings of the National Food Consumption survey, which showed that $50 \%$ of households sampled experienced hunger, 25\% were at risk of hunger and 25\% were foodsecure $^{2}$. However, food supplementation of at-risk groups is unlikely to have maximum benefit if it is not multi-focal and part of a broader package of nutrition-related interventions. These should include promotion and support for breast-feeding, adequate complementary feeding, growth monitoring and promotion, feeding during illness, de-worming and micronutrient supplementation (with iron, iodine and vitamin A). These interventions should be integrated into primary health care and supported by community-based projects ${ }^{20}$.

In conclusion, on the basis of this evaluation, it is recommended that the PEM Scheme focus on supplementation of children $<3$ years and pregnant and lactating women within the broader health facility-based programme. To ensure sustainability, more emphasis needs to be given to establishing community-based nutrition programmes that are linked to nutrition interventions at clinics. Underpinning the programme should be the initial and ongoing training of clinic staff and a standardised monitoring system. 


\section{Acknowledgements}

We would like to thank Ms L Magwentshu, Ms L van Niekerk, Ms E Immelman and all staff at the clinics in the Northern Cape who participated in the study. The study was made possible by a research grant from Health Systems Trust.

\section{References}

1 Health Systems Trust and Department of Health. Health Care in the Northern Cape: Implications for Planning. Technical Report. Durban: Health Systems Trust and Department of Health, 1996.

2 Labadarios D, ed. Supported by N Steyn, E Maunder, U MacIntyre, R Swart, G Gericke, J Huskisson, A Dannhauser, $\mathrm{HH}$ Vorster and AE Nesamvuni. The National Food Consumption Survey (NFCS): Children aged 1-9 years, South Africa, 1999. Technical Report. The National Food Consumption Survey (NFCS), Stellenbosch, 2000.

3 The South African Vitamin A Consultative Group (SAVACG). Children aged 6 to 71 months in South Africa, 1994: Their Anthropometric, Vitamin A, Iron and Immunisation Coverage Status. Isando: SAVACG, 1995.

4 Dhansay A, Hendricks M. A Literature Review and Technical Perspective of Protein Energy Malnutrition in SA and International and Local Nutrition Intervention Studies. National Research Programme for Nutritional Intervention of the Community Health Research Group. Cape Town: Medical Research Council, 1994.

5 Department of Health, Nutrition Directorate. Integrated Nutrition Programme for South Africa: Broad Guidelines for Implementation. Pretoria: Department of Health, 1998.

6 Louw HH, Khan MBM, Woods DL, Power M, Thompson MC. Perinatal mortality in the Cape Province 1989-1991. South African Medical Journal 1995; 85: 325.

7 Jennings J, Gillespie S, Mason J, Lotfi M, Scialfa T, eds. Managing Successful Nutrition Programmes. United Nations Administrative Committee on Co-ordination/SubCommittee on Nutrition (ACC/SCN) State-of-the-art Series Nutrition Policy Discussion Paper No. 8. A report based on the ACC/SCN workshop at the 14th IUNS International Nutrition Congress on Nutrition, Seoul, South Korea, 20-25 August 1989. Geneva: ACC/SCN, September, 1992.

8 Mora JO, de Paredes B, Wagner M, de Navarro L, Suescuan J, Christiansen $\mathrm{N}$, et al. Nutritional supplementation and the outcome of pregnancy. I Birth weight. American Journal of Clinical Nutrition 1979; 32: 455-62.
9 Mora JO, Herrera MG, Suescun J, de Navarro L, Wagner M. The effects of nutritional supplementation on the physical growth of children at risk of malnutrition. American Journal of Clinical Nutrition 1981; 34: 1885-92.

10 Stefanak MA, Jarjoura D. Weight gain in supervised and takehome feeding programmes in Chad. Journal of Tropical Pediatrics 1989; 35: 214-7.

11 Hendricks M, Perez E, Roberts M, Weight M. A prospective study of the growth of children under five years receiving a nutrition supplement at a malnutrition clinic. South African Journal of Epidemiology and Infection 2000; 15(2): 32-5.

12 Malek E. An Evaluation of the Protein Energy Malnutrition Scheme for Children under 6 years of age in the Mitchell's Plain District of the Western Cape Province. Unpublished report, 1997.

13 Rivera JA, Habicht JP, Robson DS. Effect of supplementary feeding on recovery from mild to moderate wasting in preschool children. American Journal of Clinical Nutrition 1991; 54: 62-8.

14 Beaton G. Which age groups should be targeted for supplementary feeding? In: Nutritional Issues in Food Aid. United Nations Administrative Committee on Co-ordination/Sub-Committee on Nutrition (ACC/SCN) Nutrition Policy Discussion Paper No. 12. Papers from a Symposium held at ACC/SCN 19th Session hosted by the World Food Programme, Rome, 24-25 February 1992. Geneva: ACC/SCN.

15 Uauy R, Kain J. The epidemiological transition: need to incorporate obesity prevention into nutrition programmes. Public Health Nutrition 2002; 5(1A): 223-9.

16 Gayle HD, Dibley MJ, Marks JS, Trowbridge FL. Malnutrition in the first two years of life. American Journal of Diseases in Childhood 1987; 141: 531-4.

17 Lechtig A, Habicht JP, Delgado H, Klein RE, Yarbrough C, Martorell R. Effect of food supplementation during pregnancy on birth weight. Pediatrics 1975; 56(4): 508-20.

18 Kusin JA, Kardjatis S, Houtkooper JM, Renqvist UH. Energy supplementation during pregnancy and postnatal growth. Lancet 1992; 340: 623-6.

19 Gonzalez-Cossio T, Habicht JP, Delgado H, Rasmussen KM. Food supplementation during lactation increases milk intake and the proportion of exclusive breastfeeding. FASEB Journal 1991; 5: A917.

20 Allen LH, Gillespie SR, eds. What Works? A Review of the Efficacy and Effectiveness of Nutrition Interventions. United Nations Administrative Committee on Co-ordination/SubCommittee on Nutrition (ACC/SCN) Nutrition Policy Discussion Paper No. 19/Asian Development Bank (ADB) Nutrition and Development Series No. 5. Geneva-Manila: ACC/SCN in collaboration with the ADB, 2001. 